\title{
Probiotic Bacillus pumilus SE5 shapes the intestinal microbiota and mucosal immunity in grouper Epinephelus coioides
}

\author{
Hong-Ling Yang ${ }^{1}$, Han-Qin Xia ${ }^{2}$, Yi-Dan Ye ${ }^{1,2}$, Wen-Chao Zou ${ }^{2}$, Yun-Zhang Sun ${ }^{1,2, *}$ \\ ${ }^{1}$ The Key Laboratory of Healthy Mariculture for the East China Sea, Ministry of Agriculture, Fisheries College, \\ Jimei University, Xiamen 361021, PR China
}

${ }^{2}$ Xiamen Key Laboratory for Feed Quality Testing and Safety Evaluation, Fisheries College, Jimei University, Xiamen 361021, PR China

\begin{abstract}
The health benefits of probiotics are thought to occur, at least in part, through an improved intestinal microbial balance in fish, although the molecular mechanisms whereby probiotics modulate the intestinal microbiota by means of activation of mucosal immunity are rarely explored. In this study, the effects of viable and heat-inactivated probiotic Bacillus pumilus SE5 on the intestinal dominant microbial community and mucosal immune gene expression were evaluated. The fish were fed for $60 \mathrm{~d}$ with 3 different diets: control (without probiotic), and diets T1 and T2 supplemented with $1.0 \times 10^{8}$ cells $\mathrm{g}^{-1}$ viable and heat-inactivated B. pumilus SE5, respectively. Upregulated expression of TLR1, TLR2 and IL-8, but not MyD88 was observed in fish fed the viable probiotic, while elevated expression of TLR2, IL-8 and TGF- 31 , but not MyD88 was observed in fish fed the heat-inactivated $B$. pumilus SE5. The induced activation of intestinal mucosal immunity, especially the enhanced expression of antibacterial epinecidin-1, was consistent with the microbial data showing that several potentially pathogenic bacterial species such as Psychroserpens burtonensis and Pantoea agglomerans were suppressed by both the viable and heat-inactivated probiotic $B$. pumilus SE5. These results lay the foundation for future studies on the molecular interactions between probiotics, intestinal microbiota and mucosal immunity in fish.
\end{abstract}

KEY WORDS: Bacillus pumilus - Intestinal microbiota - Mucosal immunity - Toll-like receptor · Epinephelus coioides

Resale or republication not permitted without written consent of the publisher

\section{INTRODUCTION}

The increased intensification of marine fish aquaculture has led to a high number of disease outbreaks with an increasing range of bacterial pathogens. Traditional disease control strategies employ antibiotics and chemical disinfectants, but these are no longer recommended practices due to the emergence of bacterial resistance, and also due to concerns over environmental impacts (Merrifield et al. 2010). Therefore, the use of probiotics has been suggested as an alternative method for the prevention and control of various diseases in aquaculture (Merrifield et al. 2010,
Ringø et al. 2010). Recently, the potential of using probiotics for disease control, immune stimulation and growth promotion have been demonstrated in grouper Epinephelus spp., one of the most important mariculture fish species in China and Southeast Asian countries (Son et al. 2009, Sun et al. 2010, 2011, Harikrishnan et al. 2010). Our research group observed that Bacillus pumilus SE5 was a dominant bacterium in the gut of fast growing grouper Epinephelus coioides and exhibited in vitro antagonistic activity against several fish pathogens (Sun et al. 2009). Subsequently, an in vivo study confirmed that viable $B$. pumilus SE5 could improve the feed utilization and immune responses 
(Sun et al. 2010) and modulate the gut microbiota of juvenile E. coioides (Sun et al. 2011).

Although the mechanisms are not well understood, Merrifield et al. (2010) suggests that the benefits of probiotics in fish are achieved, at least in part, via improving the host intestinal microbial balance. However, little information is available about the molecular mechanisms by which probiotics modulate the gut microbiota of fish through the activation of mucosal immunity. In homothermic animals, it is generally accepted that toll-like receptors (TLRs) of the intestinal mucosal immune system can recognize microbial-associated molecular patterns (MAMPs) shed by commensal microbes/probiotics and activate signalling cascades that finely tune the production of cytokines and antimicrobial proteins depending on the signals delivered by the microbes, which helps to establish a balanced microbial community (Abreu 2010, Sánchez de Medina et al. 2013). It has been proposed that the fish mucosal immune system may have a similar response to probiotics, but little information is available (Pérez et al. 2010, Rombout et al. 2011).

Viable probiotics modulating the intestinal microbiota of fish has been extensively reported (TapiaPaniagua et al. 2010, Ferguson et al. 2010, Sun et al. 2011, Liu et al. 2013). Interestingly, several recently published studies have demonstrated that certain dead probiotics can modulate the gut microbial community of fish (Hoseinifar et al. 2011, Mohapatra et al. 2012) and improve gut mucosal immunity (Salinas et al. 2008, Pan et al. 2008, Forberg et al. 2012). As the dead probiotics could not compete for nutritional substances, nor secrete inhibitory substances in the gut, the most likely mechanism whereby the dead probiotics modulate gut microbiota is by activating the mucosal immune system of host. Therefore, dead probiotics could be good research subjects to study the molecular mechanisms in interactions between probiotics, gut microbiota and mucosal immunity in fish. In the present study, therefore, the effects of viable and heat-inactivated probiotic $B$. pumilus SE5 on the intestinal microbiota and mucosal immune gene expression in E. coioides were evaluated.

\section{MATERIALS AND METHODS}

\section{Probiotic strain and diet preparation}

Probiotic Bacillus pumilus SE5 was isolated from the gut of juvenile grouper Epinephelus coioides (Sun et al. 2009), and cultured and prepared as described previously (Sun et al. 2009, 2010). After incubation, the cells were harvested and resuspended in phosphate-buffered saline. The number of bacteria in the suspension was $1.0 \times 10^{10}$ cells $\mathrm{ml}^{-1}$, which was determined by plate counting on tryptone soya agar (TSA) at $28^{\circ} \mathrm{C}$ for $48 \mathrm{~h}$. Part of the live bacterial suspension was heat-inactivated in a water bath at $95^{\circ} \mathrm{C}$ for $60 \mathrm{~min}$, and non-viability was checked by plating on TSA.

In our previous studies, probiotic B. pumilus SE5 in a generally accepted dose $\left(1.0 \times 10^{8} \mathrm{CFU} \mathrm{g}{ }^{-1}\right)$ has been confirmed to be effective in improving the feed efficiency and immune response (Sun et al. 2010), and modulating the gut microbiota of grouper E. Coioides (Sun et al. 2011). In the present study, therefore, the same dose $\left(1.0 \times 10^{8} \mathrm{CFU} \mathrm{g}^{-1}\right)$ was used to assess the effect of viable and heat-inactivated SE5 on the intestinal microbiota and mucosal immune gene expression in E. coioides. The basal diet was formulated as described in Sun et al. (2011). Probiotic diets T1 and T2 were prepared by gently spraying the required amount of viable and heat-inactivated bacterial suspensions, respectively, on the control diet and mixing it part-by-part in a 3-dimensional drum mixer (SYH-100, Punaier Drying Equipment) to obtain a final probiotic concentration of $1.0 \times 10^{8}$ cells $\mathrm{g}^{-1}$. Dietary ingredients of the probiotic and control diets were mixed with required amount of water and then cold press extruded (CD4XITS extruder, South China University of Technology) to produce $5 \mathrm{~mm}$ pellets. The counts of SE5 in the T1 and T2 diets after extrusion were determined by spread plating on TSA as described in Sun et al. (2011); a high probiotic level $\left(0.96 \times 10^{8} \mathrm{CFU} \mathrm{g}^{-1}\right)$ was observed in the $\mathrm{T} 1$ diet, while no viable SE5 was observed in the T2 diet.

\section{Experimental design}

The animal trial in this study followed the protocols approved by animal care and use committee of Jimei University, China. Juvenile grouper E. coioides were obtained from a local commercial farm and transported to the Aquaculture Research Aquarium, Jimei University. The feeding experiment was conducted in nine 1801 seawater fiberglass tanks, each connected to an open circulating system (30 $\mathrm{g} \mathrm{l}^{-1}$ salinity, at $26 \pm$ $2{ }^{\circ} \mathrm{C}$, mean $\pm \mathrm{SE}$ ). Each tank was randomly stocked with 25 fish $(14.57 \pm 0.05 \mathrm{~g})$ and each treatment was conducted in triplicate. The fish were fed the control diet, viable probiotic containing diet (treatment T1) and heat-inactivated probiotic containing diet (treatment T2), respectively. The feeding level was 3\% biomass $d^{-1}$ provided in equal rations at 09:00 and 
17:00 $\mathrm{h}$ for $60 \mathrm{~d}$. At the end of the trial (Day 60), 3 fish were taken randomly from each tank, and thus a total of 9 fish were collected per treatment. The intestine of each fish was aseptically excised and the digesta was removed under sterile conditions as described by Sun et al. (2011). Three intestinal samples per treatment (1 sample from each tank) were kept in Eppendorf tubes at $-80^{\circ} \mathrm{C}$ for DNA extraction and microbial analysis, and the other 6 intestinal samples per treatment ( 2 samples from each tank) were stored at $-80^{\circ} \mathrm{C}$ in TRIzol reagent (Invitrogen) for RNA extraction and immune gene analysis. It should be noted that one of the experimental aims, not presented in this study, was to evaluate the effect of probiotic treatment on growth performance. This accounts for the disparity in the number of fish used and number of fish sampled for microbiota and immunological analyses.

\section{Bacterial community analysis}

The dominant bacterial communities of 3 individual fish in each group (fish C1, C2 and C3 in the control group, fish V1, V2 and V3 in the viable probiotic group and fish D1, D2 and D3 in the heat-inactivated probiotic group) were analyzed. Total DNA extraction, PCR, denaturing gradient gel electrophoresis (DGGE) and sequencing were conducted as described in Sun et al. (2011). DGGE fingerprints were analyzed using Quantity One v.4.6.3 analyses software (Bio-Rad Laboratories). Levels of similarity between fingerprints were calculated according to the Dice similarity coefficient and the unweighted pair group method with arithmetic averages (UPGMA) was used to create a dendrogram. The resulting sequences were compared with the sequences from the National Center for Biotechnology Information (NCBI) using the BLAST sequence algorithm to retrieve the closest known alignment identities. The sequences reported in this study have been deposited in the GenBank database under the following accession numbers: KC991203, KC991208，KC991211，KC991212，KC991215，KC991217, KC991221, KC991222, KC991223, KC991225, KC991229, KC991233 and KC991234.

\section{Immune genes expression analysis}

Intestinal tissues were homogenized and total RNA was extracted from each homogenized tissue sample by the TRIzol extraction method according to the manufacturer (Invitrogen). Quantification was carried out with a NanoDrop 1000 (Thermo Scientific) and the quality of the RNA was checked with a Bioanalyzer (Agilent technologies). To remove DNA, $1.5 \mu \mathrm{g}$ RNA were treated with $2 \mu$ l DNase, $2 \mu l$ DNase buffer and appropriate RNase free water (Sigma) in a final volume of $11 \mu \mathrm{l}$ according to the protocol of the manufacturer (Promega). Subsequently, first-strand cDNA was synthesized using a TIANscript RT Kit (Tiangen). Briefly, the DNase treated RNA was mixed with $1 \mu \mathrm{l}$ random primer (Sangon). The mix was first incubated at $70^{\circ} \mathrm{C}$ for $5 \mathrm{~min}$ and then rapidly cooled on ice for $2 \mathrm{~min}$. Next, the solution containing $1 \mu$ l Ribolock RNase Inhibitor, $1 \mu \mathrm{l}$ Quant reverse transcriptase, $4 \mu \mathrm{l}$ $10 \times$ Reaction buffer, $1 \mu \mathrm{l}$ dNTP mix (10 mM each nucleoside) and $1 \mu \mathrm{l}$ RNase free water in a final volume of $20 \mu \mathrm{l}$ was incubated at $37^{\circ} \mathrm{C}$ for $1 \mathrm{~h}$.

The mucosal immune genes, such as TLR1, TLR2, TLR5, MyD88, IL-1 $\beta$, IL-8, TGF- $\beta 1$, epinecidin-1 and IgM, were determined using RT-qPCR with specific primers as previously reported (Table 1 ). $\beta$-actin was selected as the housekeeping gene for data normalization, as it has been extensively reported to be a good housekeeping gene for $E$. coioides gene expression studies (Xu et al. 2010, Wei et al. 2011). The RT-qPCR was performed with the SYBR Green Realtime PCR Master Mix (Toyobo) in an ABI 7500 real-time PCR Detection system (Applied Biosystems). The total volume of the PCR reactions was $20 \mu \mathrm{l}$ and consisted of $10 \mu \mathrm{l} 2 \times$ SYBR GreenIRealtime PCR Master Mix, $0.5 \mu \mathrm{l}$ primer of each, $2 \mu \mathrm{l}$ cDNA, and $7 \mu \mathrm{l}$ deionized $\mathrm{H}_{2} \mathrm{O}$. The cycling conditions were as follows: $95^{\circ} \mathrm{C}$ for $1 \mathrm{~min}$ and then 40 cycles of $95^{\circ} \mathrm{C}$ for $15 \mathrm{~s}$ and $60^{\circ} \mathrm{C}$ for $60 \mathrm{~s}$. All RT-qPCRs were performed at least 3 times.

\section{Statistical analysis}

The data of expression of immune genes from 6 fish are presented as fold increases (mean $\pm \mathrm{SE}$ ). Data were examined by 1-way analysis of variance (ANOVA). When ANOVA identified differences among groups, a multiple comparison (Duncan's) test was conducted to examine significant differences among treatments using Statistical Package for Social Science (SPSS), release 14.0. Significant differences were declared at $\mathrm{p} \leq 0.05$.

\section{RESULTS}

\section{Bacterial community}

The autochthonous bacterial compositions of intestinal samples from 3 fish fed either the control 
Table 1. Real-time PCR primers used for immune genes of the grouper Epinephelus coioides

\begin{tabular}{|c|c|c|c|}
\hline Gene & Nucleotide sequence $\left(5^{\prime}-3^{\prime}\right)$ & Accession no. & Reference \\
\hline$\beta$-actin & $\begin{array}{l}\text { Fw: GAC ATC AAG GAG AAG CTG TG } \\
\text { Rev: TGC TGT TGT AGG TGG TCT CGT }\end{array}$ & AY510710 & Wei et al. (2011) \\
\hline TLR1 & $\begin{array}{l}\text { Fw: CCA GGG TCG CAG AGT CCT ATC } \\
\text { Rev: GCC AGC CAA GTT CAG TTT CGT }\end{array}$ & HM357229 & Wei et al. (2011) \\
\hline TLR2 & $\begin{array}{l}\text { Fw: AGG GTT CAG AAG GGT TGC TAT } \\
\text { Rev: CAG GAA GGA AGT CCC GTT TGT }\end{array}$ & HM357230 & Wei et al. (2011) \\
\hline TLR5 & $\begin{array}{l}\text { Fw: CTG ACC CTG ATG CTT TTC G } \\
\text { Rev: GCT ACT TTA CTG CTG TGT G }\end{array}$ & GH612592 & $\mathrm{Xu}$ et al. (2010) \\
\hline MyD88 & $\begin{array}{l}\text { Fw: AGC TGG AGC AGA CGG AGT G } \\
\text { Rev: GAG GCT GAG AGC AAA CTT GGT C }\end{array}$ & GQ202584 & Wei et al. (2011) \\
\hline IL-1 $\beta$ & $\begin{array}{l}\text { Fw: AGG ATG CCT GAG GGA CTG } \\
\text { Rev: GGT AAT CGT CTC CAG ATG TAA }\end{array}$ & EF582837 & Lu et al. (2008) \\
\hline IL-8 & $\begin{array}{l}\text { Fw: GCA AGC TTG GCG TTT TTT GGT GTT GGC CAT } \\
\text { Rev: CTG GGT ACC ATG AGC AGC AGA GTC ATT GTC }\end{array}$ & FJ913064 & Hu et al. (2010) \\
\hline TGF $\beta 1$ & $\begin{array}{l}\text { Fw: CAC CTA CAT CTG GAA TGC TGA AAA C } \\
\text { Rev: CTG CTC CAC CTT GTG TTG CCT GC }\end{array}$ & ACV96791 & Ping et al. (2011) \\
\hline Epinecidin-1 & $\begin{array}{l}\text { Fw: CAT CGC CCT CTT TCT TGT GTT G } \\
\text { Rev: CCC TCC CCG GGT TCA G }\end{array}$ & BQ096584 & Pan et al. (2007) \\
\hline $\operatorname{Ig} M$ & $\begin{array}{l}\text { Fw: ACC GTG ACC CTG ACT TGC TAT G } \\
\text { Rev: CCC GAT GGA CCT GAC AAT AGC }\end{array}$ & AY875500 & Cui et al. (2010) \\
\hline
\end{tabular}

or probiotic diets were analyzed by PCR-DGGE (Fig. 1). The DGGE profiles revealed complex and highly reproducible bacterial communities in the 3 individual fish of each treatment. Different DGGE patterns were observed in samples collected from the probiotic treatments and the control. Six DGGE bands (bands 1, 5, 7, 8, 9 and 18) were common to all samples from the control and both probiotic treatments, 6 bands (bands 2, 4, 11, 12, 15 and 17) were present only in the control group, while bands 3 and 10 were present only in treatment T1 (viable probiotic), and band 16 only in treatment T2 (heat-inactivated probiotic) (Fig. 1), suggesting a decrease in bacterial diversity in the 2 probiotic treatments. A dendrogram representing the similarity of the microbial profiles from the PCR-DGGE fingerprints is displayed in Fig. 2, which was in accordance with the DGGE profiles and demonstrated that the 2 probiotic triplicates were generally clustered into 1 group distinctly different from the control triplicate with the exception of 1 sample (fish D3) in treatment T2.

Eighteen predominant bands (bands 1 to 18) that appeared on the DGGE gel were excised and 13 bands were successfully sequenced. The resulting sequences were compared with data from the NCBI using the BLAST sequence algorithm and the results are shown in Table 2. Bands 2, 4, 11, 12 and 17 were present only in the control group, and

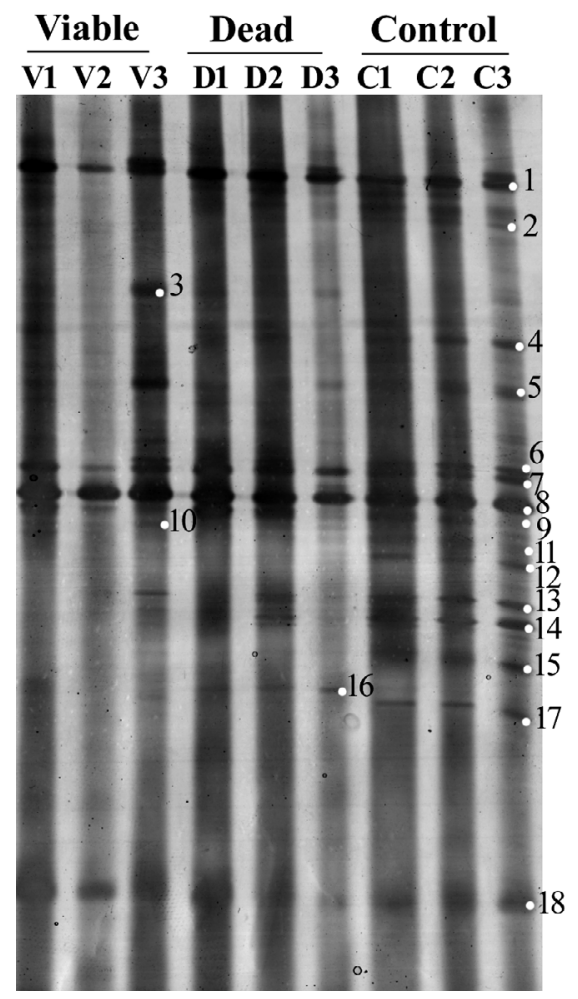

Fig. 1. PCR-DGGE fingerprints showing diversity of autochthonous intestinal microbiota of grouper Epinephelus coioides fed the control diet (C1, $\mathrm{C} 2$ and $\mathrm{C} 3)$, viable Bacillus pumilus SE5 (V1, V2 and V3) and heat-inactivated SE5 (D1, D2 and D3) 


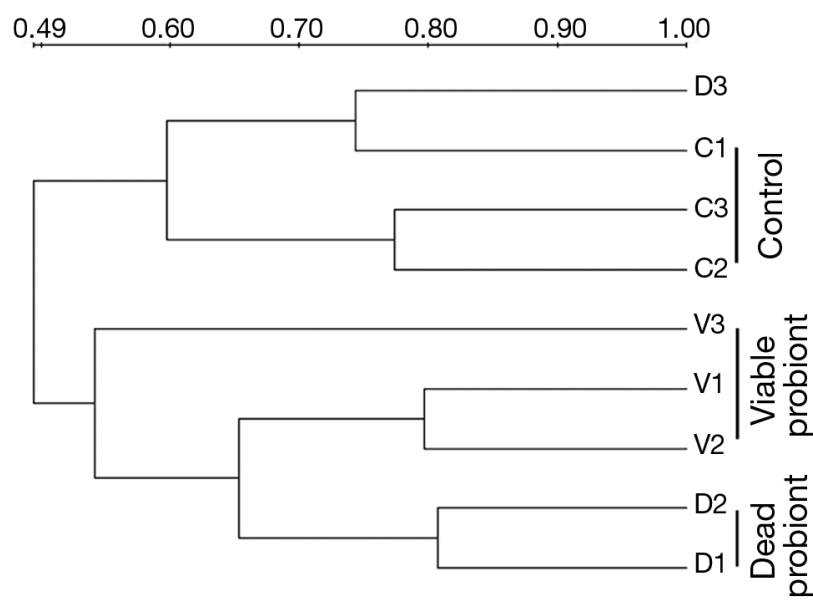

Fig. 2. Similarity dendrogram of PCR-DGGE fingerprints of autochthonous intestinal microbiota of grouper Epinephelus coioides fed the control diet (C1, C2 and C3), viable Bacillus pumilus SE5 (V1, V2 and V3) and heat-inactivated SE5 (D1, D2 and D3)

most closely related to uncultured Shigella sp. isolate DGGE gel band GYC43-3-like, Psychroserpens burtonensis ACAM181-like, uncultured gamma proteobacterium clone Fuku2-SW-PH56-like, Pantoea agglomerans isolate EB17-like and uncultured bacterium clone 080521-40-like bacterium, respectively. Bands 3 and 10 were only present in the T1 treatment and were closely related to Photobacterium sp. HDC28-like and uncultured bacterium isolate DGGE gel band 5-5-like bacterium, respectively, while band 16 was only present in the T2 treatment and showed $99 \%$ similarity to uncultured gamma proteobacterium clone 06ICW-like bacterium.

\section{Expression of mucosal immune genes}

TLR expression data acquired from RT-qPCR are presented in Fig. 3, which demonstrates that the TLR1 expression in the T1 treatment was upregulated significantly compared with the control $(\mathrm{p}<0.05)$, while no significant difference was observed in the $\mathrm{T} 2$ treatment. The TLR2 expression in treatments T1 and T2 increased significantly compared with the control $(\mathrm{p}<$ 0.05), while the TLR5 expression in treatments T1 and $\mathrm{T} 2$ showed a significant downregulation $(\mathrm{p}<0.05)$.

Adaptor MyD88 involved in the TLR signalling pathways has been shown to play an important role in resistance to bacterial infections. In this study, the expression of MyD88 in treatments T1 and T2 showed no significant difference compared with the control (Fig. 4).

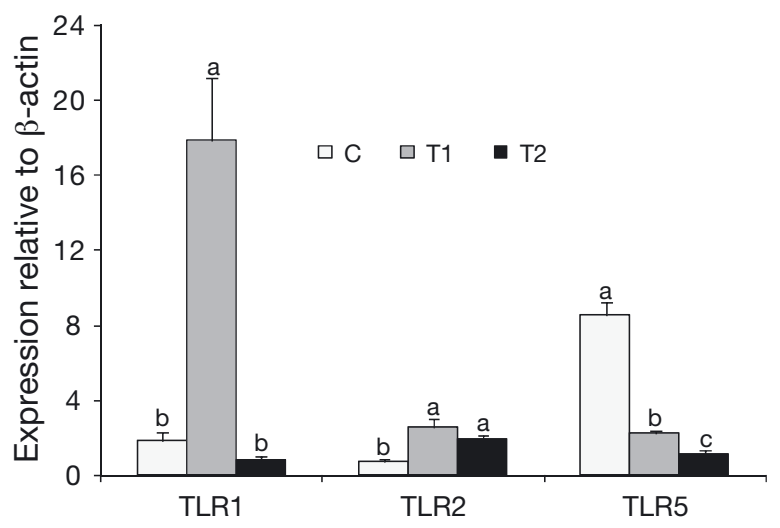

Fig. 3. Expression of toll-like receptors (TLR1, TLR2 and TLR5) in the intestine of grouper Epinephelus coioides fed the control diet $(\mathrm{C})$, viable probiotic Bacillus pumilus SE5 (T1) and heat-inactivated SE5 (T2) for $60 \mathrm{~d}$. Each bar represents the mean $( \pm \mathrm{SE})$ value from 6 determinations $(n=6)$. Data with different letters are significantly different $(p<0.05)$

Table 2. Closest relatives of intestinal bacteria in grouper Epinephelus coioides fed control, viable and heat-inactivated Bacillus pumilus SE5 as determined by a BLAST search of sequences generated for the bands in the DGGE gel (see Fig. 1). Percentage similarities to the closest relatives, and their accession numbers, are given

\begin{tabular}{|lllr|}
\hline Band no. & Accession no. & Closest relative & Similarity (\%) \\
\hline 1 & KC991221 & Uncultured Escherichia sp. isolate DGGE band N5 & 100 \\
2 & KC991203 & Uncultured Shigella sp. isolate DGGE gel band GYC43-3 & 100 \\
3 & KC991217 & Photobacterium sp. HDC28 & 99 \\
4 & KC991223 & Psychroserpens burtonensis ACAM181 & 99 \\
7 & KC991208 & Enterobacter sp. CTSP22 & 92 \\
9 & KC991215 & Marine bacterium HC-17 & 100 \\
10 & KC991222 & Uncultured bacterium isolate DGGE gel band 5-5 & 89 \\
11 & KC991233 & Uncultured gamma proteobacterium clone Fuku2-SW-PH56 & 97 \\
12 & KC991234 & Pantoea agglomerans isolate EB17 & 93 \\
13 & KC991225 & Uncultured bacterium clone F1Q32TO03DV1RL & 100 \\
16 & KC991229 & Uncultured gamma proteobacterium clone 06ICW & 99 \\
17 & KC991211 & Uncultured bacterium clone 080521-40 & 100 \\
18 & KC991212 & Vibrio ruber strain GHt9-5 & 100 \\
\hline
\end{tabular}




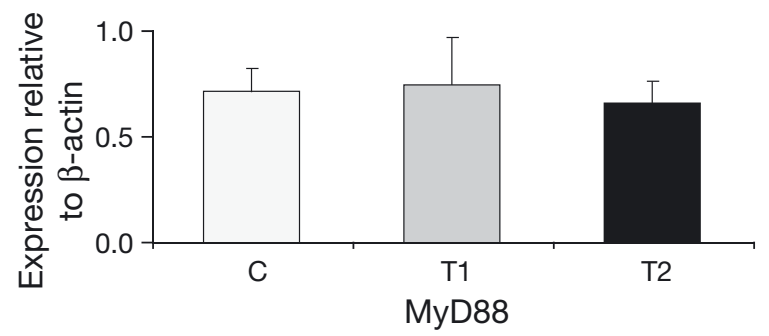

Fig. 4. The expression of adaptor MyD88 in the intestine of grouper Epinephelus coioides fed the control diet (C), viable probiotic Bacillus pumilus SE5 (T1) and heat-inactivated SE5 (T2) for $60 \mathrm{~d}$

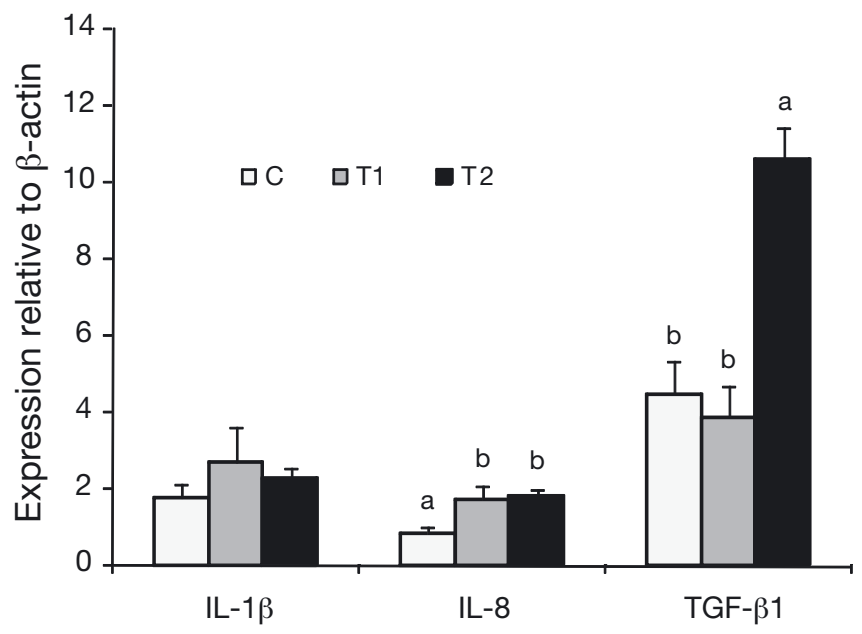

Fig. 5. The expression of cytokines (IL-1 $\beta$ and IL-8 and TGF$\beta 1$ ) in the intestine of grouper Epinephelus coioides fed the control diet (C), viable probiotic Bacillus pumilus SE5 (T1) and heat-inactivated SE5 (T2) for $60 \mathrm{~d}$. Each bar represents the mean $( \pm \mathrm{SE})$ value from 6 determinations $(n=6)$. Data with different letters are significantly different $(p<0.05)$

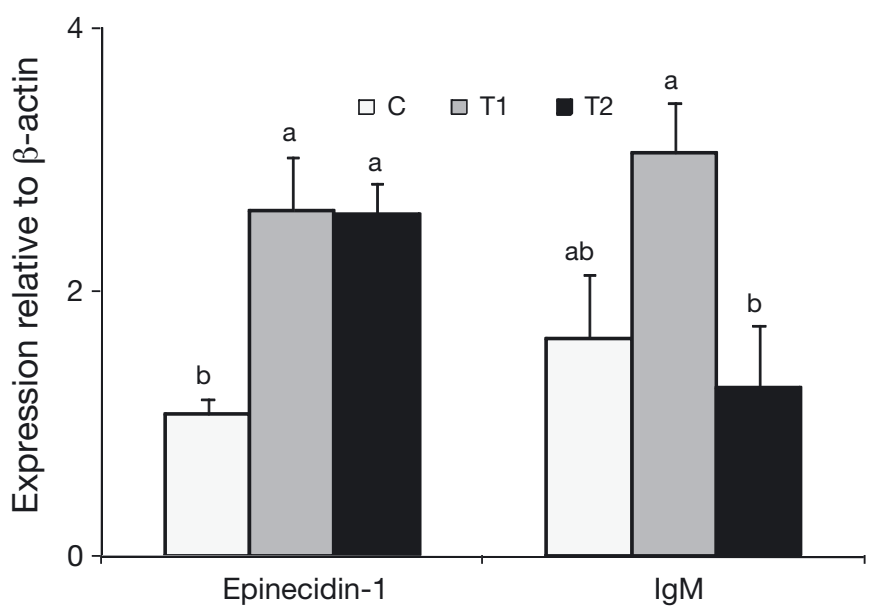

Fig. 6. The expression of antibacterial proteins (epinecidin-1 and $\operatorname{IgM}$ ) in the intestine of grouper Epinephelus coioides fed the control diet $(\mathrm{C})$, viable probiotic Bacillus pumilus SE5 (T1) and heat-inactivated SE5 (T2) for $60 \mathrm{~d}$. Each bar represents the mean $( \pm \mathrm{SE})$ value from 6 determinations $(n=6)$. Data with different letters are significantly different $(p<0.05)$
The expression of cytokine genes, including the pro-inflammatory cytokines (IL-1 $\beta$ and IL-8) and anti-inflammatory cytokine (TGF- $\beta 1)$, was assessed by RT-qPCR (Fig. 5). In treatment T1, IL-8 expression increased significantly ( $p<0.05$ ), while IL-1 $\beta$ and TGF- $\beta 1$ expression showed no significant difference compared with the control. In treatment T2, IL-8 and TGF- $\beta 1$ expression showed a significant upregulation $(p<0.05)$, while IL-1 $\beta$ expression increased slightly, but was not statistically significant.

The expression of genes for 2 antibacterial proteins, epinecidin-1 and IgM, was determined by RTqPCR (Fig. 6). The expression of epinecidin-1 in treatments T1 and T2 was enhanced significantly compared with control ( $\mathrm{p}<0.05)$, while increased IgM expression was observed in treatment $\mathrm{T} 1$, but the increase was not statistically significant.

\section{DISCUSSION}

It has been extensively demonstrated that viable probiotics can shape the gut microbiota in fish (Tapia-Paniagua et al. 2010, Ferguson et al. 2010, Sun et al. 2011, Liu et al. 2013), but little attention has been paid to the impact of dead probiotics on the microbial community (Hoseinifar et al. 2011, Mohapatra et al. 2012). Using cultivation-based techniques, Hoseinifar et al. (2011) reported that dietary administration of commercial inactive brewer's yeast Saccharomyces cerevisiae var. ellipsoideus elevated the level of lactic acid bacteria, the most common types of beneficial microorganisms in the gut of fish (Ringø et al. 2010), and that this could positively affect host health and immunity. Interestingly, both the viable and heat-killed mixed probiotics (Bacillus subtilis, Lactococcus lactis and $S$. cerevisiae) significantly reduced the total heterotrophic bacterial population in the intestine of Labeo rohita, but the response was more rapid and substantial with the viable probiotics (Mohapatra et al. 2012). In line with the previous studies, both the viable and heat-inactivated Bacillus pumilus SE5 decreased the diversity of dominant intestinal microbial populations, as several bacteria (corresponding to bands 2, 4, 11, 12, 15 and 17) were suppressed to undetectable levels in the intestine of Epinephelus coioides. Among those suppressed bacteria, Psychroserpens burtonensis (corresponding to band 4) has been suggested as a potential opportunistic pathogen associated with salmonid amoebic gill disease (Bowman \& Nowak 2004), while Pantoea agglomerans (corresponding to band 12) is a known enteric pathogenic bacterium to fish (Hansen et al. 
1990, Austin \& Austin 2012). These results suggest that both the viable and heat-inactivated $B$. pumilus SE5 controlled those potentially pathogenic bacteria, and this may benefit the health of host. Obviously, the heat-inactivated probiotic cannot suppress pathogenic bacteria by competition for nutritional substances or secretion of inhibitory substances. Therefore, we presume that the most likely mechanism whereby the heat-inactivated probiotic modulates the gut microbiota is by means of activating the mucosal immunity of fish, as several heat-inactivated probiotics have exhibited promising mucosal immunomodulatory activity in various fish species (Nayak 2010, Pérez et al. 2010).

It is generally accepted that TLR signalling pathways in mammals play essential roles in the recognition of the probiotics and activation of the mucosal immune system (Abreu 2010, Sánchez de Medina et al. 2013). However, the roles of fish TLRs in probioticinduced mucosal immune response have received relatively little attention until recently (Pérez et al. 2010). In this study, TLR1, TLR2 and TLR5, which have been suggested to be involved in probiotic recognition and mucosal immune activation in homothermic animals (Sánchez de Medina et al. 2013), were determined by RT-qPCR. Significantly elevated expression of TLR1 and TLR2 was observed in fish fed the viable $B$. pumilus SE5, while the expression of TLR2 was upregulated in fish fed the heatinactivated SE5. The enhanced TLR2 expression induced by both the viable and heat-inactivated SE5 may result from the interaction of the host with the probiotic MAMPs, such as lipoprotein/lipopeptides, peptidoglycan and lipoteichoic acid (Sánchez de Medina et al. 2013). Interestingly, we noticed that the heat-inactivated SE5 failed to upregulate the expression of TLR1, suggesting that heat treatment may affect the probiotic MAMPs and impair the efficacy of the probiotic. Moreover, the expression of TLR5 decreased significantly in fish fed both the viable and heat-inactivated $B$. pumilus SE5. While the exact mechanisms are not clear, we proposed 2 possible reasons. Firstly, TLR5 reacts only with flagellin, (Sánchez de Medina et al. 2013). B. pumilus SE5 does not have flagellin and therefore has no impact on the expression of TLR5. Secondly, both the viable and heat-inactivated B. pumilus SE5 have been shown to decrease the levels of several bacteria with flagella, such as Shigella sp. (corresponding to band 2) and $P$. agglomerans (corresponding to band 12) (Holt 1994, Girón 1995), which may tune the expression of TLR5.

Although the expression of adaptor MyD88 was not affected, the expression of pro-inflammatory cyto- kine (IL-8) was upregulated in fish fed the viable B. pumilus SE5, while the expression of IL-8 and antiinflammatory immune gene (TGF- $\beta 1$ ) was enhanced in fish fed the heat-inactivated SE5. In line with our results, the expression of pro-inflammatory cytokines (IL-1 $\beta$, IL-6, IL-17A/F-3, TNF- $\alpha$ and TNF-N) and anti-inflammatory cytokines (IL-10 and TGF- $\beta 1$ ) in Japanese pufferfish Takifugu rubripes head kidney (HK) cells was generally upregulated after 1, 4, 8, 12, 24 and $48 \mathrm{~h}$ of incubation with 2 heat-killed bacteria, namely Lactobacillus paracasei spp. paracasei (strain 06TCa22) and L. plantarum (strain 06CC2) (Biswas et al. 2013). In contrast, Lazado et al. (2010) reported that after $3 \mathrm{~h}$ of incubation with Atlantic cod Gadus morhua HK leukocytes, viable Psychrobacter sp. GP12 upregulated the expression of IL-1 $\beta$ and IL-8, but the heat-inactivated GP12 failed to do so. Therefore, different probiotic strains and different forms of one probiotic may exert different impacts on the expression of cytokines in fish, and future studies should pay more attention to the molecular interactions between the probiotics and host immune system.

Teleost fish possess a rich repertoire of antimicrobial peptides (AMPs), which are able to kill pathogens by interacting directly with their negatively charged membranes, disrupting the osmotic balance of the microbial membrane (Pan et al. 2007, Broekman et al. 2013). In vitro studies showed that the dead autochthonous probiotic Lactobacillus sp. elicited a significant expression of cathelicidin in the Atlantic cod cell line (Broekman et al. 2013). In line with the previous study, our in vivo study demonstrated that the expression of epinecidin-1 was upregulated in the intestine of $E$. coioides fed both the viable and heat-inactivated B. pumilus SE5, and this is consistent with intestinal microbiota data showing that several bacteria (including potentially pathogenic $P$. burtonensis and P. agglomerans) decreased to undetectable levels in fish fed both the viable and heat-inactivated probiotic. As the heat-inactivated probiotic could not modulate the intestinal microbiota by mechanisms such as competition for nutritional substances and secretion of inhibitory substances, we speculate that the probiotic-induced activation of intestinal mucosal immunity, especially the significantly upregulated expression of antibacterial peptides, may play an important role in the intestinal microbiota modulation.

In conclusion, both the viable and heat-inactivated probiotic $B$. pumilus SE5 shape the intestinal microbiota and mucosal immune gene expression in grouper E. coioides. The probiotic-induced activation 
of intestinal mucosal immunity, especially the activation of antibacterial epinecidin-1, may play an important role in the intestinal microbiota modulation in E. coioides. This work lays the foundation for future studies on the molecular interactions between probiotics, gut microbiota and mucosal immunity in fish.

Acknowledgements. This work was supported by the Program for New Century Excellent Talents in Fujian Province University (Grant No. JA13167), the Natural Science Foundation of Fujian Province of China (2014J01130), the Xiamen Key Laboratory Project (Grant No. 3502Z20120013, No. 3502Z20130040), the Foundation of Shang-Da Li in Jimei University (Grant No. ZC2011010) and the Foundation for Innovative Research Team of Jimei University (Grant No. 2011A001).

\section{LITERATURE CITED}

Abreu MT (2010) toll-like receptor signalling in the intestinal epithelium: how bacterial recognition shapes intestinal function. Nat Rev Immunol 10:131-144

Austin B, Austin DA (2012) Bacterial fish pathogens: disease of farmed and wild fish, 5th edn. Springer, New York, NY

> Biswas G, Korenaga H, Nagamine R, Takayama H and others (2013) Cytokine responses in the Japanese pufferfish (Takifugu rubripes) head kidney cells induced with heat-killed probiotics isolated from the Mongolian dairy products. Fish Shellfish Immunol 34:1170-1177

$>$ Bowman JP, Nowak B (2004) Salmonid gill bacteria and their relationship to amoebic gill disease. J Fish Dis 27: 483-492

Broekman DC, Guðmundsson GH, Maier VH (2013) Differential regulation of cathelicidin in salmon and cod. Fish Shellfish Immunol 35:532-538

Cui M, Zhang Q, Yao Z, Zhang Z, Zhang H, Wang Y (2010) Immunoglobulin $\mathrm{M}$ gene expression analysis of orangespotted grouper, Epinephelus coioides, following heat shock and Vibrio alginolyticus challenge. Fish Shellfish Immunol 29:1060-1065

> Ferguson RMW, Merrifield DL, Harper GM, Rawling MD and others (2010) The effect of Pediococcus acidilactici on the gut microbiota and immune status of on-growing red tilapia (Oreochromis niloticus). J Appl Microbiol 109: 851-862

- Forberg T, Vestrum RI, Arukwe A, Vadstein O (2012) Bacterial composition and activity determines host geneexpression responses in gnotobiotic Atlantic cod (Gadus morhua) larvae. Vet Microbiol 157:420-427

Girón JA (1995) Expression of flagella and motility by Shigella. Mol Microbiol 18:63-75

Hansen GN, Raa J, Olafsen JA (1990) Isolation of Enterobacter aglomerans from dolphin fish, Coryphaena hippurus L. J Fish Dis 13:93-96

Harikrishnan R, Balasundaram C, Heo MS (2010) Molecular studies, disease status and prophylactic measures in grouper aquaculture: economic importance, diseases and immunology. Aquaculture 309:1-14

Holt JG (1994) Bergey's manual of determinative bacteriology, 9th edn. Williams \& Wilkins, Baltimore, MD

> Hoseinifar SH, Mirvaghefi A, Merrifield DL (2011) The effects of dietary inactive brewer's yeast Saccharomyces cerevisiae var. ellipsoideus on the growth, physiological responses and gut microbiota of juvenile beluga (Huso huso). Aquaculture 318:90-94

$\mathrm{Hu}$ YF, Sun J, Lin XT, Liang H (2010) Gene cloning and expression of Interleukin-8 (IL-8) from orange-spotted grouper (Epinephelus coioides). J Jinan Univ (Nat Sci) 31:324-330

> Lazado CC, Caipang CM, Gallage S, Brinchmann MF, Kiron V (2010) Expression profiles of genes associated with immune response and oxidative stress in Atlantic cod, Gadus morhua head kidney leukocytes modulated by live and heat-inactivated intestinal bacteria. Comp Biochem Physiol B Biochem Mol Biol 155:249-255

Liu W, Ren P, He S, Xu L, Yang Y, Gu Z, Zhou Z (2013) Comparison of adhesive gut bacteria composition, immunity, and disease resistance in juvenile hybrid tilapia fed two different Lactobacillus strains. Fish Shellfish Immunol 35:54-62

> Lu DQ, Bei JX, Feng LN, Yong Z and others (2008) Interleukin-1 $\beta$ gene in orange-spotted grouper, Epinephelus coioides: molecular cloning, expression, biological activities and signal transduction. Mol Immunol 45:857-867

> Merrifield DL, Dimitroglou A, Foey A, Davies SJ and others (2010) The current status and future focus of probiotic and prebiotic applications for salmonids. Aquaculture 302:1-18

Mohapatra S, Chakraborty T, Prusty AK, Das P, Paniprasad K, Mohanta KN (2012) Use of different microbial probiotics in the diet of rohu, Labeo rohita fingerlings: effects on growth, nutrient digestibility and retention, digestive enzyme activities and intestinal microflora. Aquacult Nutr $18: 1-11$

> Nayak SK (2010) Probiotics and immunity: a fish perspective. Fish Shellfish Immunol 29:2-14

- Pan CY, Chen JY, Cheng YS, Chen CY and others (2007) Gene expression and localization of the epinecidin-1 antimicrobial peptide in the grouper (Epinephelus coioides), and its role in protecting fish against pathogenic infection. DNA Cell Biol 26:403-413

Pan X, Wu T, Song Z, Tang H, Zhao Z (2008) Immune responses and enhanced disease resistance in Chinese drum, Miichthys miiuy (Basilewsky), after oral administration of live or dead cells of Clostridium butyrium CB2. J Fish Dis 31:679-686

Pérez T, Balcázar JL, Ruiz-Zarzuela I, Halaihel N, Vendrell D, de Blas I, Múzquiz JL (2010) Host-microbiota interactions within the fish intestinal ecosystem. Mucosal Immunol 3: 355-360

Ping HL, Wu JY, Xu SW, Hu KS, Duan ZG (2011) Molecular cloning and expression analysis of transforming growth factor- $\beta 1$ (TGF- $\beta 1$ ) from orange-spotted grouper (Epinephelus coioides). Acta Sci Natur Univ Sunyatseni 50: 92-98 (in Chinese with English Abstract)

> Ringø E, Løvmo L, Kristiansen M, Bakken Y and others (2010) Lactic acid bacteria vs. pathogens in the gastrointestinal tract of fish: a review. Aquacult Res 41:451-467

Rombout JHWM, Abelli L, Picchietti S, Scapigliati G, Kiron V (2011) Teleost intestinal immunology. Fish Shellfish Immunol 31:616-626

Salinas I, Abelli L, Bertoni F, Picchietti S and others (2008) Monospecies and multispecies probiotic formulations produce different systemic and local immunostimulatory effects in the gilthead seabream (Sparus aurata L.). Fish Shellfish Immunol 25:114-1123

Sánchez de Medina F, Ortega-González M, González-Pérez R, Capitán-Cañadas F, Martínez-Augustin O (2013) 
Host-microbe interactions: the difficult yet peaceful coexistence of the microbiota and the intestinal mucosa. Br J Nutr 109:S12-S20

Son VM, Chang CC, Wu MC, Guu YK, Chiu CH, Cheng W (2009) Dietary administration of the probiotic, Lactobacillus plantarum, enhanced the growth, innate immune responses, and disease resistance of the grouper Epinephelus coioides. Fish Shellfish Immunol 26:691-698

Sun YZ, Yang HL, Ling ZC, Chang JB, Ye JD (2009) Gut microbiota of fast and slow growing grouper Epinephelus coioides. Afr J Microbiol Res 3:713-720

Sun YZ, Yang HL, Ma RL, Lin WY (2010) Probiotic applications of two dominant gut Bacillus strains with antagonistic activity improved the growth performance and immune responses of grouper Epinephelus coioides. Fish Shellfish Immunol 29:803-809

Sun YZ, Yang HL, Ma RL, Song K, Lin WY (2011) Molecular analysis of autochthonous microbiota along the digestive

Editorial responsibility: Catherine Collins,

Aberdeen, UK tract of juvenile grouper Epinephelus coioides following probiotic Bacillus pumilus administration. J Appl Microbiol 110:1093-1103

- Tapia-Paniagua ST, Chabrillón M, Díaz-Rosales P, de la Banda IG, Lobo C, Balebona MC, Moriñigo MA (2010) Intestinal microbiota diversity of the flat fish Solea senegalensis (Kaup, 1858) following probiotic administration. Microb Ecol 60:310-319

Wei YC, Pan TS, Chang MX, Huang B, Xu Z, Luo TR, Nie P (2011) Cloning and expression of Toll-like receptors 1 and 2 from a teleost fish, the orange-spotted grouper Epinephelus coioides. Vet Immunol Immunopathol 141: 173-182

Xu D, Wei J, Cui H, Gong J, Yan Y, Lai R, Qin Q (2010) Differential profiles of gene expression in grouper Epinephelus coioides, infected with Singapore grouper iridovirus, revealed by suppression subtractive hybridization and DNA microarray. J Fish Biol 77:341-360

Submitted: October 31, 2013; Accepted: May 26, 2014 Proofs received from author(s): August 21, 2014 